\title{
Recognition and chemotherapy of oculomycosis
}

\author{
BARRIE R. JONES* \\ F.R.C.P., F.R.C.S., F.R.A.C.S. \\ YvonNe M. Clayton† \\ B.Sc., Ph.D. \\ ERASMUS O. OJI*
B.Sc., D.O., F.R.C.S. \\ British Postgraduate Medical Federation, University of London, \\ $\dagger$ Institute of Dermatology, St John's Hospital for Diseases of the Skin, London
}

\begin{abstract}
Summary
Oculomycosis may be divided into the orbital infections of phycomycosis of Aspergillus and other species and the infections of the globe. The latter comprise endogenous, post-surgical or traumatic intra-ocular infections and direct infections of the cornea: these are the commonest form of oculomycosis. They are not easy to differentiate from other, more common causes of septic infection of the eye. The early recognition of fungal infections of the eye thus rests on maintaining an efficient service for all septic infections of the eye.

Candida albicans and other dimorphic fungal infections are best treated with flucytosine combined with either polyenes such as amphotericin $B$ and natamycin or combined with imidazoles such as clotrimazole or miconazole.
\end{abstract}

Aspergillus spp. account for about $50 \%$ of the cases of filamentous fungal infection of the cornea but more than 100 species of varying pathogenicity and drug sensitivity have been implicated. Econazole, clotrimazole or miconazole combined with thiabendazole are recommended for Aspergillus spp. Econazole, thiabendazole or miconazole combined with flucytosine for Cladosporium sp. For Fusarium solani and other species econazole is the best drug but some isolates are sensitive to thiabendazole or other imidazoles.

Alternatively, filamentous fungal infections may be treated with natamycin which has a broad spectrum of activity; but does not penetrate well and, like other polyenes, should not be combined with imidazole antifungal chemotherapy because of antagonistic drug interaction.

Overall, econazole emerges as the most widely acting drug; but successful results are dependent on rather complex investigation with intensive and protracted care that can best be provided in a few centres of referral.

\section{Introduction}

Oculomycosis is of 2 main types: mycosis of the orbit and mycosis of the globe, the latter being the more common. Orbital mycosis arises by infection from the paranasal sinuses, from trauma or from endogenous metastasis. The commonest types of phycomycoses affecting the orbit are infection by Absidia spp., Mucor spp., or Rhizopus spp. in persons debilitated by severe diabetes, malignancy or toxic therapy. Aspergillus spp. and a wide variety of other fungi can also invade the orbit.

The globe may be involved in metastatic fungal endophthalmitis by Candida albicans, Cryptococcus neoformans, Coccidioides immitis, or possibly Histoplasma capsulatum and also by Aspergillus spp. or other opportunists in immunosuppressed patients.

But outside the areas where the systemic mycoses are likely to be encountered the commonest fungal infections of the eye are corneal infections and postsurgical or post-traumatic fungal endophthalmitis. There are large regional differences in prevalence but Candida spp. accounts for about $50 \%$ of the recorded cases. Of the filamentous organisms, Aspergillus spp. account for about half, and a bewildering variety of over 100 organisms accounts for the remaining cases (Jones, Richards and Morgan, 1969). Fusarium, especially $F$. solani is increasingly recognized in this group (Jones et al., 1969; Jones, Sexton and Rebell, 1969; Jones, 1975).

Keratomycosis presents as suppurative, usually ulcerative infection of the cornea, and may range in virulence from the leisurely chromoblastomycoses, through intermediate organisms like Aspergillus or Cladosporium to the most rapidly destructive $F$.

*Correspondence: Professor Barrie R. Jones, Institute of Ophthalmology, Moorfields Eye Hospital, City Road, London EC1 2PD. 
solani (Jones, 1975). Certain typical features may be present and suggest the diagnosis of keratomycosis, such as a dry, raised ulcer with crenate, spiculate or pseudo-hyphate border, or satellite lesions, recurrent hypopyon, posterior chamber endophthalmitis with progressive shallowing of the anterior chamber, or involvement of the vitreous and failure to respond to antibacterial treatment. The occasional unequivocal recognition of actual fungal hyphae in the cornea can establish a firm diagnosis but this is unusual (Jones, 1975).

However, all these typical signs may be absent, leaving fungal infection unrecognized amonst other suppurative infections of the eye. The early and rapid recognition of fungal infection of the cornea therefore rests on establishing and maintaining an efficient emergency service for the immediate investigation and optimal management of all suppurative infections of the globe, be they due to bacterial, fungal, acanthamoebic or viral infection (Jones and Clayton, 1978). As with other infections, early recognition is the greatest contribution to effective chemotherapy.

The recognition of a 'suppurative infection of the eye', characterized by intense polymorphonuclear infiltration, thus demands immediate and vigorous collection of specimens to detect organisms of each type in the lesions and to culture them for identification and sensitivity tests. It is important to take scrapings from the whole of the ulcer base and from the whole length and depth of the ulcer edge. Such corneas are often anaesthetic and if so should be scraped without using topical anaesthetics. Intraocular fluids may be collected by anterior chamber tap, or by vitrectomy-aspiration. Smears are stained with Giemsa and Gram stains: cultures are set up on blood agar and in thioglycollate at $37^{\circ} \mathrm{C}$ for bacteria and on Sabouraud's agar and in brain-heart infusion at $25^{\circ} \mathrm{C}$ for fungi, as well as on Culbertson's
Acanthamoeba plates at $25^{\circ} \mathrm{C}$ (Culbertson, 1961 ; Culbertson, Ensminger and Overton, 1965).

Unless the stained smears give clear proof of fungal infection, and bacteria are not seen, each case of suppurative corneal infection should be treated, in the first instance, on the assumption of being bacterial (Jones and Clayton, 1978).

If the smears show both yeast forms and filaments, there is a dimorphic fungus in the lesion, with a very high probability of its being Candida, especially $C$. albicans. This demands intensive 15min to $30-\mathrm{min}$ treatment with $1.5 \%$ flucytosine drops, so long as the cornea is ulcerated, combined

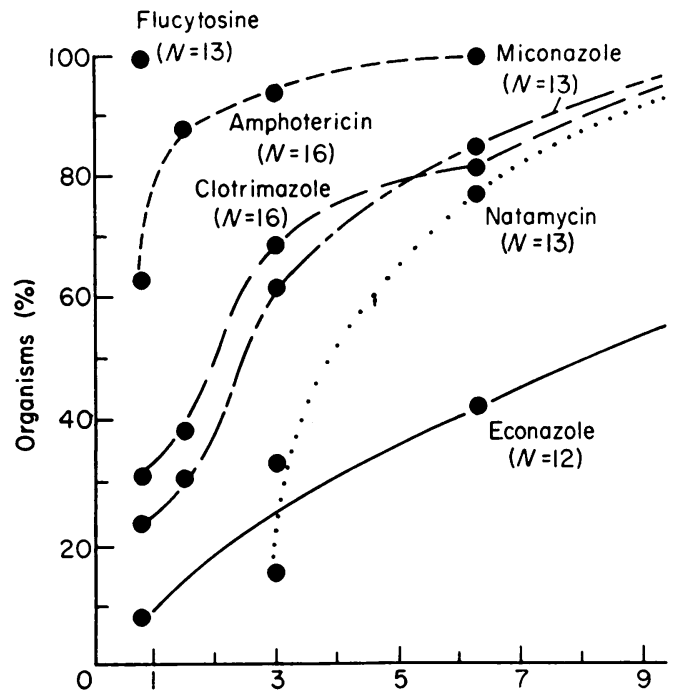

Antifungal minimal inhibitory concentration (mg/litre'

FIG. 1. Cumulative percentage sensitivity distribution curves, for various antifungal drugs, for all ocular isolates of Candida albicans and other yeasts.

TABLE 1. In vitro susceptibility of ocular fungal isolates to antifungal drugs. Values - geometric mean inhibitory concentration $\mathrm{mg} / \mathrm{l}$

\begin{tabular}{|c|c|c|c|c|c|c|c|}
\hline & Flucytosine & Amphotericin B & Natamycin & Clotrimazole & Miconazole & Econazole & Thiabendazole \\
\hline Candida albicans & $\begin{array}{r}0.75 \\
(13 / 13)\end{array}$ & $\begin{array}{c}1 \cdot 1 \\
(16 / 16)\end{array}$ & $\begin{array}{c}6 \cdot 7 \\
(15 / 15)\end{array}$ & $\begin{array}{c}2 \cdot 7 \\
(16 / 16)\end{array}$ & $\begin{array}{c}3 \cdot 1 \\
(13 / 13)\end{array}$ & $\begin{array}{c}8 \cdot 8 \\
(12 / 13)\end{array}$ & - \\
\hline Aspergillus fumigatus & $\begin{array}{c}17 \cdot 1 \\
(11 / 20)\end{array}$ & $\begin{array}{c}7 \cdot 3 \\
(38 / 42)\end{array}$ & $\begin{array}{c}9 \cdot 8 \\
(38 / 42)\end{array}$ & $\begin{array}{c}1 \cdot 3 \\
(42 / 42)\end{array}$ & $\begin{array}{c}1 \cdot 6 \\
(38 / 38)\end{array}$ & $\begin{array}{c}1 \cdot 0 \\
(34 / 34)\end{array}$ & $\begin{array}{c}6.9 \\
(7 / 7)\end{array}$ \\
\hline Cladosporium herbarum & $\begin{array}{c}1.9 \\
(6 / 8) \\
50 \\
(2 / 8)\end{array}$ & $\begin{array}{c}9 \cdot 9 \\
(9 / 9)\end{array}$ & $\begin{array}{c}9 \cdot 1 \\
(9 / 9)\end{array}$ & - & $\begin{array}{c}1 \cdot 4 \\
(8 / 8)\end{array}$ & $\begin{array}{c}0.9 \\
(7 / 7)\end{array}$ & $\begin{array}{c}1.4 \\
(9 / 9)\end{array}$ \\
\hline Penicillium spp. & - & $\begin{array}{c}11 \cdot 6 \\
(10 / 13)\end{array}$ & $\begin{array}{l}20 \cdot 0 \\
(7 / 13)\end{array}$ & $\begin{array}{c}3 \cdot 8 \\
(13 / 13)\end{array}$ & $\begin{array}{c}1.9 \\
(13 / 13)\end{array}$ & $\begin{array}{c}1 \cdot 1 \\
(13 / 13)\end{array}$ & $\begin{array}{c}2 \cdot 2 \\
(2 / 2)\end{array}$ \\
\hline $\begin{array}{l}\text { Fusarium solani and } \\
\text { other spp. }\end{array}$ & - & $\begin{array}{c}3 \cdot 9 \\
(6 / 24)\end{array}$ & $\begin{array}{c}5 \cdot 2 \\
(24 / 24)\end{array}$ & $\begin{array}{c}10 \cdot 7 \\
(18 / 20)\end{array}$ & $\begin{array}{c}10 \cdot 0 \\
(16 / 17)\end{array}$ & $\begin{array}{c}3.9 \\
(12 / 13)\end{array}$ & $\begin{array}{c}5 \cdot 0 \\
(10 / 15)\end{array}$ \\
\hline
\end{tabular}


with $1 \%$ clotrimazole in arachis oil or ointment, or $1 \%$ miconazole in similar vehicles. Alternatively candicidin $0.6 \%$ ointment may have a place; natamycin and nystatin are less active; amphotericin drops are active, but toxic for the cornea (Fig. 1). For severe or deep intra-ocular yeast infections flucytosine should also be given orally $200 \mathrm{mg} / \mathrm{kg} /$ day, and intravenous amphotericin $B$ may be required in addition; but its successful use requires meticulous precautions (Jones, 1975). Either the imidazoles: clotrimazole, miconazole or econazole; or the polyenes: amphotericin B, candicidin, natamycin or nystatin can be usefully combined with flucytosine. But imidazoles should not be given in combination with polyenes because of antagonistic drug interaction (Wingfield, 1974).

TABLE 2.

\begin{tabular}{ll}
\hline Filamentous ocular fungi: & 119 isolates tested \\
\hline Aspergillus fumigatus and other spp. & $\begin{array}{l}\text { Allescheria } \\
\text { Alternaria }\end{array}$ \\
Fusarium solani and other spp. & $\begin{array}{l}\text { Cephalosporium } \\
\text { Chaetomium } \\
\text { Dreschlera }\end{array}$ \\
& $\begin{array}{l}\text { Echinobotyrum } \\
\text { Epicoccum }\end{array}$ \\
Penicillium lilacinium and other spp. & $\begin{array}{l}\text { Mucor } \\
\text { Nigrospora } \\
\text { Paecilomyces } \\
\text { Cladosporium herbarum } \text { and other spp. }\end{array}$ \\
& $\begin{array}{l}\text { Phoma } \\
\text { Sporodonema }\end{array}$ \\
\hline
\end{tabular}

The in vitro susceptibilities of some commoner ocular fungal isolates are shown in Table 1. C. albicans represents the commonest yeast but if smears suggest a filamentous fungus this may be one of more than 100 species (Table 1). The fungus should be isolated, identified and its sensitivity tested.

For blind treatment of the entire range of 119 ocular filamentous fungal isolates tested (Table 2), including Fusarium spp. and Aspergillus spp., but excluding Candida spp. and other yeasts, the drug of choice was econazole (Fig. 2). Econazole was the most active drug for $90 \%$ of the isolates; for $94 \%$ it had a MIC* of $6.25 \mathrm{mg} / 1$ or less (for $90 / 91 \mathrm{GM} \dagger$ MIC $=1.3 \mathrm{mg} / \mathrm{l}$ ). Clotrimazole was the most active for $4 \%$ : GM MIC $=2.9 \mathrm{mg} / 1$ for $111 / 115$. Miconazole was the most active for $2 \%$ : GM MIC $=2.2 \mathrm{mg} / 1$ for $104 / 105$. Thiabendazole was the most active for $2 \%$ : GM MIC $=2.9 \mathrm{mg} / \mathrm{l}$ for $34 / 44$. Natamycin was the most active for the remaining $2 \%$ : GM MIC $=$ $7 \cdot 8 \mathrm{mg} / \mathrm{l}$ for $107 / 119$.

The evidence for efficacy in oculomycosis of each of these imidazole antifungals, as for flucytosine,

* MIC, minimal innibitory concentration

† GM, geometric mean rests on a series of anecdotal case reports (Jones, 1975); but placebo-controlled trials are not possible in this disease, and the clinical course, changing from deterioration to resolution when antifungal chemotherapy guided by sensitivity tests has been adequately implemented, makes a strong presumptive case. However, the imidazole antifungal drugs, especially econazole, clotrimazole and miconazole, become protein-bound. All antifungal chemotherapy should, if possible, commence intensively and be continued at reduced levels for a long time. The regimen of 'topical saturation therapy' using chosen imidazoles in $1-2 \%$ oily solution, with or without $1.5 \%$ flucytosine aqueous drops, is as follows:

every 15 min 1st day; every 30 min 1 st night; every $15-30$ min 2 nd-4th day; 1-4 hourly 2nd-4th night;

every $60 \mathrm{~min} 5$ th-20th day;

2-4 hourly 10th-60th day;

4-8 hourly 20th-90th day.

Two specific and 3 general points deserve mention: econazole is somewhat irritant in the eye and may not be tolerated by certain individuals; thiabendazole is best administered as an aqueous $4 \%$ suspension and is known to penetrate the eye well by this route (Robinson et al., 1966); where available, systemic administration should be combined with topical during the initial phase of therapy of deep intra-ocular mycoses; anti-inflammatory therapy

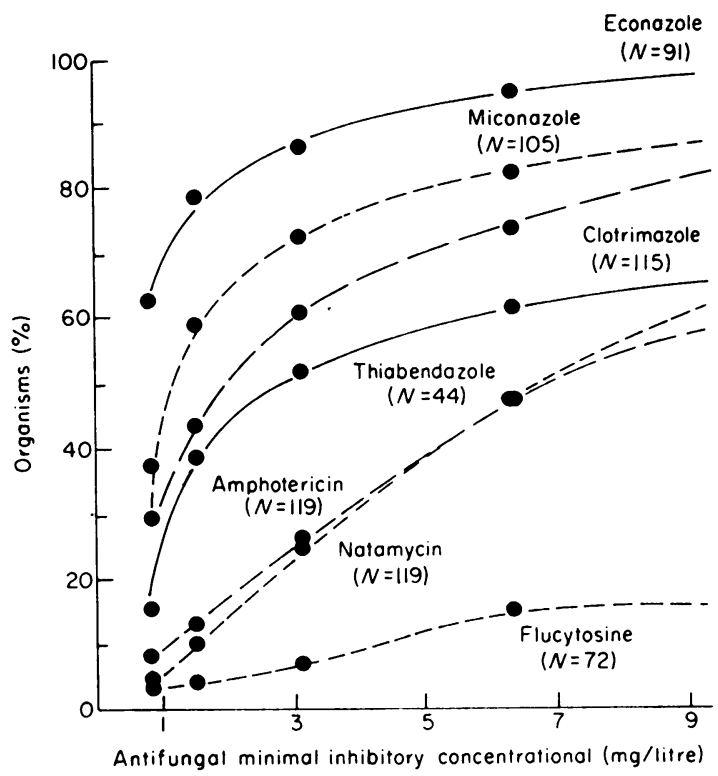

FIG. 2. Cumulative percentage sensitivity distribution curves, for various antifungal drugs, for ocular isolates of all filamentous fungi shown in Table 1, i.e. excluding Candida albicans and other dimorphic fungi. 
with prostaglandin synthetase inhibitors or corticosteroids can be beneficially combined with effective specific antifungal chemotherapy (Jones, 1975); combinations of antifungal drugs should be used in accordance with the following principles derived from unpublished in vitro work (Wingfield, 1974):

Polyene/polyene combinations, polyene/flucytosine, flucytosine/imidazole, and imidazole/imidazole combinations have each been additive when tested. On the other hand polyene/imidazole combinations have been antagonistic in respect of amphotericin B, natamycin, nystatin, etruscomycin, and clotrimazole or miconazole. The clinical course of eyes responding only to a limited degree on natamycin therapy have very commonly shown a delay of 2 or more days before showing a striking improvement on changing to more active imidazole therapy.

Guided by these principles, oculomycosis is now curable and vision can often be preserved or restored, given that the patient can remain under intensive medical and surgical care in the hands of a team that is experienced in such problems. There is thus a strong case for referral of oculomycosis to a few such centres.

Unfortunately, in the humid tropical rural world, where fungal infection is most prevalent and probably plays an important role along with bacteria in septic loss of eyes, it is not practicable to provide this specialized and prolonged intensive care. The remaining big challenge in oculomycosis is therefore to develop effective prophylaxis and to distribute prophylactic preparations efficiently for immediate use in the eye at identifiable times of high risk, such as following all eye injuries, no matter how trivial (Jones and Clayton, 1978). In this field there are important challenges that should be overcome by appropriate international co-operation in field and laboratory studies.

\section{References}

Culbertson, C.G. (1961) Pathogenic Acanthamoeba (Hartmonella). American Journal of Clinical Pathology, 5, 195.

Culbertson, C.G., Ensminger, P.W. \& Overton, W.M. (1965) Isolation of additional strains of pathogenic Hartmonella sp. (Acanthamoeba). American Journal of Clinical Pathology, 43, 383.

JONES, B.R. (1975) Principles in the management of oculomycosis. XXXI Edward Jackson Memorial Lecture. American Journal of Ophthalmology, 79, 719.

JONES, B.R. \& ClAYTON, Y.M. (1978) Fungal infection of the cornea. In: Proceedings of the XXIII International Congress of Ophthalmology, Kyoto, May, 1978. Excerpta Medica, Amsterdam.

Jones, B.R., Jones, D.B., Lim, A.S.M., Bron, A.J., Morgan, G. \& Clayton, Y.M. (1969) Corneal and intra-ocular infection due to Fusarium solani. Transactions of the Ophthalmological Society of the United Kingdom, 89, 758.

Jones, B.R., Richards, A.B. \& Morgan, G. (1969) Direct fungal infection of the eye in Britain. Transactions of the Ophthalmological Society of the United Kingdom, 89, 727.

Jones, D.B., Sexton, R. \& Rebell, G. (1969) Mycotico keratitis in South Florida: a review of thirty-nine cases $\overrightarrow{\mathbb{D}}$ Transactions of the Ophthalmological Society of the United? Kingdom, 89, 781.

Robinson, H.J., Graessle, O.E., Lehman, E.G., Kelley, K.L., Geoffroy, R.F. \& Rosenblum, C. (1966) Ocular absorption of thiabendazole- ${ }^{14} \mathrm{C}$ by the rabbit. American Journal of Ophthalmology, 62, 710.

WingFIELD, H. (1974) Laboratory studies of some fungt incriminated as opportunistic pathogens. F.I.M.L.S. thesis. 